\title{
Brand gender and consumer-based brand equity on Facebook: The mediating role of consumer-brand engagement and brand love
}

Joana CésarMachado ${ }^{a 1}$ LeonorVacas-de-Carvalho ${ }^{\mathrm{b} 1}$ Salim L.Azar ${ }^{\mathrm{c1}}$ Ana Raquel André ${ }^{\mathrm{d}}$ Barbara Pires dos Santos ${ }^{\mathrm{e}}$

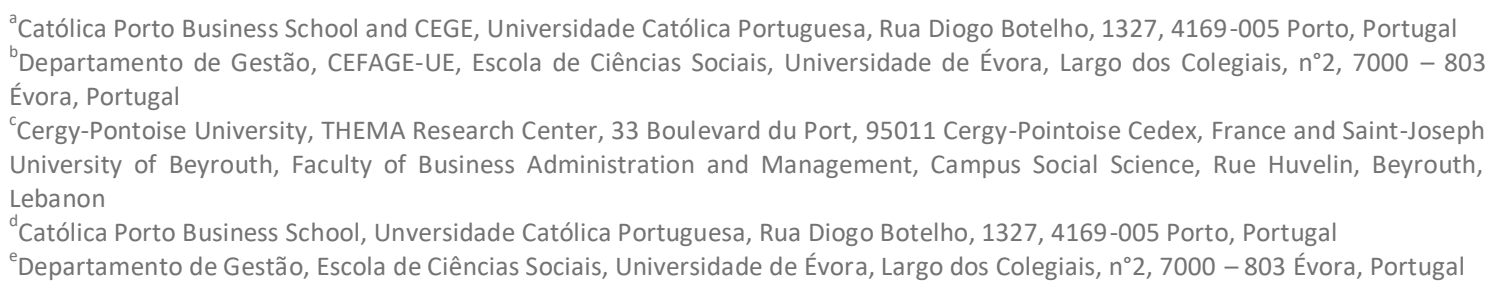

https://doi.org/10.1016/i.jbusres.2018.07.016Get rights and content

\section{Abstract}

Brand gender has been suggested as a relevant source of consumer-based brand equity (CBBE). The purpose of this paper is to deepen understanding of the relationship between brand gender and CBBE by analyzing the mediating role of consumer-brand engagement (CBE) and brand love (BL) on this relationship. This research was conducted on Facebook, the dominant global social media platform. The hypotheses were tested using structural equation modeling. Results support 6 of the 9 hypotheses, with a significant relationship between analyzed constructs. This study advances prior work by showing that brand gender has an indirect and relevant impact on CBBE through $\mathrm{BL}$ and $\mathrm{CBE}$. Therefore, this research confirms the advantages of clear gender positioning and extends prior research by suggesting that brands with a strong gender identity will encourage BL and CBE. 